\title{
Politeness in Teacher-Student Interactions in a Kenyan Secondary School Context and Implications for Pedagogy in Communication Skills
}

\author{
Joyce I. Wangia, Lydia A. Otonde \\ Department of English and Linguistics, Kenyatta University, Nairobi, Kenya \\ Email: wangia.joyce@ku.ac.ke
}

How to cite this paper: Wangia, J. I., \& Otonde, L. A. (2020). Politeness in Teacher-Student Interactions in a Kenyan Secondary School Context and Implications for Pedagogy in Communication Skills. Open Journal of Modern Linguistics, 10, 104-124.

https://doi.org/10.4236/ojml.2020.102007

Received: March 11, 2020

Accepted: April 18, 2020

Published: April 21, 2020

Copyright $\odot 2020$ by author(s) and Scientific Research Publishing Inc. This work is licensed under the Creative Commons Attribution International License (CC BY 4.0).

http://creativecommons.org/licenses/by/4.0/

(c) (i) Open Access

\begin{abstract}
It is commonly agreed that politeness is reflected in the pragmatic use of language (Brown \& Levinson, 1987). Although the politeness phenomenon is universal, with many expressional similarities, each language possesses norms and ways of expressing politeness within a given cultural context. The Kenyan school syllabus caters for the teaching of these politeness expressions across all levels of the curriculum and learners are expected to observe the same. This study sought to investigate the impact of the teaching of politeness strategies on their pragmatic use by secondary school students. Through a case study, the study looked at what strategies are used by documenting interactions in varied forums outside the classroom. The study therefore considered the verbal expressions of politeness strategies. The study finds Kenyan secondary school students limited in the use of politeness strategies and that the English language politeness strategies are at variance with the students' cultural orientation. The study makes recommendations on how learners can be better equipped in the use of politeness strategies for improved communication.
\end{abstract}

\section{Keywords}

Politeness Strategies, Pragmatics, Context, Interaction, Culture

\section{Introduction}

This study looked at student-teacher interactions to establish the use and effectiveness of politeness by the students. It was carried out in Ndigwa Secondary School in Siaya County in Western Kenya. Communication is a natural human 
activity that happens all the time. In our daily conversation, differences are seen when communicating with different social groups of people. For example, there is a higher level of informality between friends or peers than between the young and the elderly or the employees and employer. Different social situations compel us to adjust our use of language to suit the occasion.

Moreover, different communities or groups have acceptable and unacceptable ways of communicating and behaving. For example among Dholuo speakers (where this study is situated), it is deemed unfit to greet an elderly person by saying "koro" loosely translated as "how are you?" But it is normal for people of the same age or younger to greet each other the same way. Greeting that is deemed acceptable for the elderly is "oimore" and "oyaore" loosely translated as "good evening" and "good morning" respectively. This social distance and communicative behaviour is similarly expected among student-teacher interactions. In a school environment, the interlocutors do not just encounter a formal setting but they also have to grapple with a cultural shift owing to the fact that they are engaging through a second language. The linguistic/cultural nuances vary and these have to be acquired because languages vary in the way they present politeness. This aspect motivated this investigation. How do Kenyan secondary school learners portray politeness in their interactions with their teachers?

\subsection{Background to the Study}

Politeness is of importance in human interaction. When interacting with others, people desire to be affirmed, recognized and made to feel special. Every reasonable human being desires to be treated with dignity and respect. To get that treatment, the same is also expected of them. Sakr et al. (2013) state that politeness is believed to facilitate communication in human interaction as it can minimize the potential for conflict and confrontation. For social order, therefore, to occur, the notion of politeness is of importance. Brown \& Levinson (1987) state that as universal principles of human interaction, instances of politeness is reflected in language. Crystal (2008) defines language as "the systematic, conventional use of sounds, signs or written symbols in a human society for communication and self-expression" (p. 89). The use of language in context is the focus of pragmatics where politeness is an important pragmatic issue.

Students and teachers interact at different levels both in and out of school in venues like the classroom, dormitory assemblies, guidance and counselling meetings, staffroom and during games and other co-curricular activities. Outside the classroom, Ndigwa Secondary School operates as follows; every Wednesday, house assembly sessions are conducted. They run for between 20 - 30 minutes. During these sessions, students voice their grievances, and then inspections are done by both house teachers and prefects and resolutions on how to better the stay in the house are arrived at. Guidance and counselling meetings are organized every fortnight by the guidance and counselling department. These are 
conducted per class and the sessions are between 30 minutes and 1 hour depending on the topic of discussion. Lastly, daily staffroom interactions are mostly outside classroom hours when students do consultations or when discipline cases are handled. Interaction in this case is an event during which people communicate with others verbally, that is interaction through spoken or written language.

Teachers constantly observe that students are impolite with reference to the language they use. For example, a student responds to a teacher with a statement like; "of course I must go home! I have no shoes, they got lost." In such a case, the response appears impolite because of the words "of course" and "must" which are more of commanding than requesting. At other times, students during interaction with their teachers find it hard to keep saying sorry or if they say it, it appears insincere and the teacher might feel offended since in his/her judgment, the student is not really sorry from their tone of voice.

Ndigwa Secondary School is a day school hence most students are from the nearby catchment areas. The students speak Dholuo, Kiswahili, Sheng, and English with varying levels of competency in the latter. English is the medium of instruction right from upper primary school to tertiary level. However, several studies have shown that many Kenyan learners still haven't acquired enough competencies in English by the time they are entering secondary school or even graduating from it. The language policy in Ndigwa Secondary School which is speaking in English and Kiswahili only is met by a lot of challenges including mother tongue interference as majority of the learners are not fluent in either of the two.

Use of politeness strategies is part of the Kenya Institute of Curriculum Development (KICD) (2002) English syllabus in Kenya. Both primary and secondary school syllabuses for English have stipulated the various polite forms that a student should have learnt by the time a student completes the twelve year course. According to KICD (2002) English syllabus, by the time a student completes form four, helshe should have studied the following politeness markers; thank you, excuse me, sorry, and please. They should also be conversant with telephone etiquette, appropriate choice of register, interrupting and disagreeing politely, negotiation skills and turn taking which are deemed important social skills by curriculum developers. KICD (2002: p. 3) syllabus, states that in teaching of English, the emphasis should be on the acquisition of communicative competence and not simply on the passing of examination. In fact, becoming proficient in the language is a desirable life-long goal. This therefore means that in their interaction with teachers, students should be able to use these politeness markers which enhance the strategies appropriately. This study therefore addresses a number of issues such as, does the use of politeness strategies improve with the length of instruction? How do the power relations between students and teachers play out in the use of politeness strategies? Given that different cultures express politeness differently, does the prescribed syllabus reflect this and/or how could it? 


\subsection{Statement of the Problem}

This study looked at students' politeness strategies during out of class interaction with their teachers. General observations about impoliteness in students during student-teacher interactions triggered the interest for this investigation. The English subject syllabus reveals that students are taught polite forms from primary up to secondary school level. This study examined Ndigwa Secondary School students to determine how they either maintained cooperative interaction or precipitated strained interaction with their teachers. Given that the notion of politeness and politeness strategies adopted by speakers as well as the contextual factors that influence these choices ultimately determine the degree of effectiveness of an interaction, to what extend are secondary school students able to exhibit pragmatic competency in the use of politeness strategies in their second language?

\section{Literature Review}

The politeness phenomena being at the centre of human interaction has been extensively studied and hence, a lot of literature has been generated. This section looks at some of the related literature to the current study.

\subsection{Politeness Phenomenon}

Politeness is showing awareness of another person's public self-image (Yule, 1996). According to Brown \& Levinson (1978), politeness helps in human cooperation, in that it is basic to production of social order. Therefore, to understand politeness, the theories under-lying it should match with the foundation of human social life. Politeness deals with human interaction. This therefore means that there must be some universal principles. For example, one universal fact is that no one likes to be treated impolitely. Furthermore, politeness is expressed both linguistically and non-linguistically. For instance when in one instance, a student addresses a teacher as Sir and in another instance a Christian bows when getting into and out of church, both are expressing politeness.

Politeness universality applies to any general public on the planet, paying little heed to the level of its seclusion or separation, or the multifaceted nature of its social and monetary life. However, different behaviours are viewed differently from place to place or culture to culture. An instance is seen among the Dholuo speaking community where when one is offered food and he/she declines and even goes ahead to say thank you, it is still not viewed as politeness. To this community food is not declined since it is offered out of kindness, whereas according to Ethiopians, when it comes to eating, the host or hostess will not be disgraced if one refuses or leaves uneaten food on his/her plate. In fact, to eat everything from a plate is impolite. To the Ethiopian traditional community, whenever somebody goes to somebody else's house, the host offers something to eat or drink even though he/she does not want to do so (Hassen, 2016).

Green (1996) makes a distinction between polite behaviour and rude beha- 
viour. Polite behaviour makes people feel comfortable, whereas rude behaviour makes people feel uncomfortable. This is a universal fact. It therefore means to make people comfortable or to avoid making them uncomfortable, politeness is one choice.

Yule (1996) argues that politeness could be treated as a fixed concept, that is, an idea of polite social behaviour or etiquette within one particular culture. However, it is observed that possible specification for being polite in social interaction within a particular culture can occur. The underlying assumption of this possibility is that people are generally aware of the existence of politeness and rudeness and that is why what is considered polite in a church set up and in a school set up are specific and may be different from one society to another. Thus, it can clearly be seen that politeness and its universal principles are possessed by a particular society. Everyone needs to be treated politely. The difference only stems from the ways of expressing polite linguistic and non linguistic behaviour. This study identified the students' linguistic politeness strategies in student-teacher interaction.

\section{Studies on Politeness in Different Settings}

Politeness phenomena as a part of pragmatics have drawn attention of many researchers especially since Brown \& Levinson published its universality in 1978. In the past three or so decades, a vast amount of research both locally and internationally have attempted to investigate linguistic politeness; in particular, Brown \& Levinson's (1987) face-saving view of politeness stimulated a lot of discussion and controversy.

Ojwang (2009) in his study on patients claiming their rights analyzed utterances from a Kenyan hospital. He observed that there was widespread public perception that nurses in Kenya's public health facilities are rude and impolite towards their clients. This study revealed that the patient-nurse interaction was mostly non-cordial. Our study, like Ojwang' (2009) study adopted Brown \& Levinson's (1987) Politeness Theory.

Another related study, Jiang's (2010) case study of teacher's politeness in EFL class, in which both the teacher and learners are Chinese with Chinese culture, discussed linguistic politeness; that is, the ways the teacher expresses politeness verbally through her use of language. The conclusions drawn were that politeness does exist in this EFL class; politeness promotes the mutual understanding and harmonious relationship between teacher and students; politeness enhances teaching and benefits the students; politeness contributes to the effective interaction and friendly, lively atmosphere in EFL classroom. While Jiang (2010) studied politeness in a formal classroom setting, this study considers politeness in an informal/natural setting in school.

Cai et al. (2014) in the study of college teachers' politeness strategy revealed that positive strategy is preferable to negative strategy. The observation made is that positive politeness is oriented towards an individual's positive self-image and emphasizes the need for association between teachers and students. Adop- 
tion of positive energy by the teacher reduces the imminent threat of FTAs and shortens the distance between teachers and students. In conclusion, the study reveals that teachers place much emphasis on the positive politeness which can cause teachers to fulfil students' positive face and spare their negative face by offering assistance, affirming comprehension of students' needs, appearing for students when they experience issues or when they endure shame. All in all, the investigation uncovers that teachers place much accentuation on the utilization of politeness systems. The study adopted Brown \& Levinson's (1987) politeness model and collected data through observation and recording. The current study adopted the same but in contrast focused on interaction outside the classroom but in the school system.

Mwarania (2010) in her study on communicative competence: use of polite forms in a case study of Kaaga Girls' High School concluded that the students know the polite forms that they are supposed to know at this stage of acquisition of education as other researchers for example Gleason \& Weintraub (1978), have found out. Researchers and those involved with education can capitalize on this fact and use it to ensure that the students use politeness strategies. The students also use the various polite forms that are there in English. Students, however, use these polite forms sometimes in their speech as it was found out in a taped data from what they talked about in the classes and in the offices and not always, but when they deem it necessary to do so as Brown \& Levinson (1978) have said. The current study focused on the school system and the polite forms taught.

Mburu (2011) in the study on sociolinguistic differences in the use of polite forms by standard seven pupils in Machakos municipality concludes that there are differences in the way boys and girls use polite formulas. It therefore confirms to some extent what scholars have posited on various occasions, that women and men use polite formulas differently. Ndigwa Secondary School is a mixed school; the study found minor differences in politeness strategies between the boys and girls.

Maisiba (2015) in his study forms of politeness in Ekegusii: A sociolinguistic perspective, analyzed the forms of politeness in Ekegusii, how Ekegusii varies depending on power relations and the context of usage. The study just like the current study also collected data using tape recording and participant observation. The data were transcribed and analyzed in order to meet the set objectives. Unlike the current study where analysis of the data was done employing only qualitative analysis, Maisiba (2015) employed both qualitative and quantitative methods of data analysis, basing on Brown and Levinson's (1978) Politeness theory; Sacks, Schegloff, \& Jefferson (1974) Conversational Analysis theory.

M'mbohi (2016) in his study on emerging language use patterns among male football viewers in Baringo County, Kenya, focuses also on positive and negative politeness strategies. This paper also deals with positive and negative politeness strategies. M'mbohi's (2016) study however, provides further insight into the way men use language in social contexts whereas the current study hopes to provide insight on the importance of students applying politeness during stu- 
dent-teacher interactions.

\subsection{Theoretical Framework}

This study adopted Politeness Theory by Brown \& Levinson (1987). This Theory has a long history in linguistic research focusing on interaction. Brown \& Levinson (1987) define politeness as redressive action taken to counter balance the disruptive effects of face threatening acts (FTAS). FTAS are verbal or non-verbal acts that run contrary to the face wants of addressees. Face is the public self image that people want to claim for themselves. A face is a want that everyone desires to be satisfied. For this reason, interlocutors make an effort to preserve their face and that of their interactants by taking actions that reduce the threat posed by FTAS in an interaction.

Face threatening acts infringe on a hearer's need to maintain his/her self esteem and to be respected. For example, if a student walks up to a teacher and informs him/her, "I am going to the market." The teacher might feel justified to conclude that the student is impolite as they do not try to use an utterance that implies to the teacher that he/she is not imposing his/her wishes with impunity.

Brown \& Levinson (1978) suggest a number of politeness strategies to minimize the threat posed by FTAS. These strategies are: negative politeness, on record which involves doing the FTA without redressive action, positive politeness, bald on record, off-record whereby a speaker does the FTA indirectly and doing the FTA with redressive action. Avoiding the FTA altogether is also a politeness strategy.

To decide on the strategy to adopt, speakers consider the relative weightings of three wants. These are: to communicate the content of the FTA, to be efficient and urgent, to maintain the addressee's face to any degree. In this paper we consider both the positive and negative strategies that interactants used to mitigate the adverse effects of FTAS.

Positive politeness recognizes the need of the other person to be respected, confirms that they are friendly and expresses group reciprocity. It is directed to an addressee's perennial desire that their wants or actions, acquisitions and values should be thought of as desirable. It therefore attends to people's need to be appreciated and approved of.

Brown and Levinson (1987) have identified fifteen positive politeness strategies that communicators use to convey approval of their hearer's wants and to convey that their own wants are similar. These strategies fall into three general types: 1) the speaker can claim common ground with the hearer; 2) the speaker and hearer are co-operators; and 3) the speaker can fulfil the hearer's want. These three types of positive redress are conveyed through these fifteen different strategies: Notice; Exaggerate; Intensify interest to $\mathrm{H}$; Use in-group identity markers; Seek agreement; Avoid disagreement; Presuppose/raise/assert common ground; Joke; Assert or presuppose S's knowledge of and concern for H's wants; Offer/promise; Be optimistic; Include both S and $\mathrm{H}$ in the activity; Give (or ask 
for) reasons; Assume or assert reciprocity and, Give gifts to $\mathrm{H}$.

Negative politeness is redressive action addressed to the hearer's negative face i.e. their want to have freedom of action unhindered and their attention unimpeded. It is avoidance based and refers to the communicative strategies interactants use to express recognition of others' need for freedom from restraint. Realizations of negative politeness consist in assurances that the speaker recognizes and respects the addressee's negative face wants and will not or will only minimally interfere with it. Brown \& Levinson (1987) developed ten different negative politeness strategies: Be conventionally indirect; Question, hedge; Be pessimistic; Minimize the imposition; Give deference; Apologize; Impersonalize S and $\mathrm{H}$; State the FTA as a general rule; Nominalize and, Go on record as incurring a debt, or as not indebting $\mathrm{H}$.

During student-teacher interactions, students tend to use polite forms based on the situation they are in. The polite forms the students used are then categorized into positive and negative politeness.

A number of factors determine the strategy one uses. These are:

1) Social distance between parties (systematic relation). This has an influence on the type of the strategy to be used. For example, when speaking to people who are very close in terms of relationship to a person, one may choose to use positive rather than negative politeness strategy.

2) Power relations between parties (asymmetrical relations). People take into consideration the social ranking of their interlocutors when choosing a particular politeness strategy. They are likely to speak to their social equals differently from those whose status is higher or lower than theirs in a given situation.

3) The absolute ranking of the danger of the FTA. A few impositions are more prominent than others. Profoundly forcing acts like solicitations request more change to relieve their expanded risk level.

However, it is prudent to note some of the criticisms levelled against this theory. For instance, Watts (2003) points out that the formula devised to measure the weightiness of a FTA is a constructed etic which is very difficult to intuitively imagine being carried out by a speaker. Eelen (2001) also criticizes on Brown and Levinson's apparent neglect of impoliteness are merely two sides of the same coin, and therefore any theory that pretends to say something valuable about one side, automatically needs to deal with the other side as well.

Ethnocentricity is also a commonly discussed criticism. It is claimed that Brown and Levinson (1987) aims to "account for the observed cross-cultural similarities in the abstract principles which underlie polite usage". However, what exactly is meant by the term "culture" is never fully explicated thus making vague the boundaries of their framework. Ide, (1989) says people in a culture choose strategies of politeness according to the cultural expectation and requirement.

Nevertheless, Politeness Theory is pertinent in providing the strategies adopted by the study and the backdrop against which data obtained from Ndigwa Sec- 
ondary School students were analyzed, interpreted and discussed. Special attention was given to the use of politeness markers that these students had been taught since primary school level.

\section{Methodology}

A qualitative descriptive design was used. This study was carried out in Ndigwa Secondary School of Siaya County, Kenya. It is a mixed day and boarding school that was started in 1965. It is a two-streamed school with a population of five hundred and eighty five students. It has twelve teachers posted by Teachers Service Commission [TSC] and five employed by Board of Management. The target population was 300 form 1 and 3 students.

\subsection{Sampling and Sample Size}

Three settings were purposively selected namely: house assembly meetings, guidance and counselling sessions and staffroom interactions for data elicitation.

The sample size consisted of a total of 45 forms 1 and 3 students who engaged in the student-teacher interactions in the three settings. The teachers were purposively sampled by virtue of the fact that they performed the roles on those domains. Several recordings were done over a period of two weeks but in each setting, the researchers purposively analyzed specific conversations based on audibility, content and features to be studied.

Observation schedules were used by the researchers. Several recordings were done over a period of two weeks but in each setting, the researcher purposively analyzed specific conversations based on audibility, content and features to be studied. In the staffroom interactions, five conversations were analyzed, while in the guidance and counseling sessions and house assembly sessions, two recordings each were analyzed.

\subsection{Data Collection Methods and Instruments}

In order to collect data on the politeness strategies, this study applied interview method and participant observation through a structured observation guide which laid out the parameters that guided the observation such as who initiated the interaction, the class of the interactants, and the settings of the interaction. Tape recording was used to capture the utterances supplemented with field notes. Due diligence was followed regarding ethical consideration by obtaining prior consent from the participants as well as research authorization organs.

The interactions were characterized by a number of non-verbal features of communication such as nodding, smiling, waving, drooping of shoulders, shaking of the head and so on. As the conversations were going on, the exact points where the features occurred were noted. For example, if a speaker said: "I agree, and this utterance was accompanied by raised eye brows, the note taken down read: "I agree" (raised eyebrows). The non-verbal cues helped to supplement meaning in verbal communication observed. 
Interference was overcome by taking of supplementary notes on the general topic under discussion and non-verbal features, which accompanied the data. This made it possible to transcribe the data. The interactions in the dormitory assembly sessions and guidance and counseling meetings were two sessions. Each session per setting was 25 - 30 minutes. A total of two sessions for each setting was recorded. Staffroom sessions were shorter but the whole conversation was recorded and analyzed. It was not limited to two sessions but the researcher selected one with many interactions. The researchers made notes on the non-verbal behavior of the informants which helped to analyze the rest of the data. The field notes helped to capture some of the non verbal behavior that helped to supplement the recorded interactions.

\section{Data Analysis and Discussion}

The data was collected from form 3 and 4 students of Ndwiga secondary school, Kenya. Several abbreviations have been used in reference to the setting (SI Staffroom Interaction, GS Guidance and Counselling Session, HA House Assembly Session). Teachers and students are identified as $\mathrm{T}$ and $\mathrm{S}$ respectively and where more than one is involved they are numbered. Use of bold type face in the different excerpts is meant to highlight the forms of politeness evident, whereas the exact words spoken in either Dholuo or Kiswahili are in italic type face. The translations of the exact words spoken are placed under round brackets. The square brackets enclose the directions, while the curly brackets enclose non verbal cues expressing politeness.

\subsection{Students' Positive Politeness Strategies in Student-Teacher Interactions in Ndigwa Secondary School}

Brown and Levinson identify 15 categories of positive politeness strategies. This study was able to identify 7 of these in the data collected. These are going to form the basis for our analysis and discussion below We use the first four to draw specific examples. The data are coded in this way: Staffroom Interactions (SI), House Assembly Session (HA) and Guidance and Counselling Session (GS).

Table 1 gives a list of the number of times the positive politeness strategies were evident in the interactions.

According to the frequency column (number of times evident), guidance and counselling session has the highest number of strategies used, with house assembly having the least. This clearly shows that the use of the positive politeness strategies varies depending on the setting.

We will now examine samples from the first four strategies for our discussion.

\subsubsection{Use of In-Group Identity Markers}

Strategy 4 was used a total of 10 times, in the two out of three settings. It was completely not evident in staffroom interaction and only evident once in the house assembly session. Use of in-group identity marker involves a speaker (S) implicitly claiming common ground with another speaker/hearer $(\mathrm{H})$ carried by 
Table 1. Students' positive politeness strategies evident in student-teacher interactions outside the classroom setting.

\begin{tabular}{llccc}
\hline & & \multicolumn{3}{c}{ Frequency (No. of Times Evident) } \\
\cline { 3 - 5 } No. & \multicolumn{1}{c}{ Positive Politeness Strategies } & $\begin{array}{c}\text { Staffroom } \\
\text { Interactions } \\
(\mathrm{SI})\end{array}$ & $\begin{array}{c}\text { House Assembly } \\
\text { Sessions } \\
\text { (HA) }\end{array}$ & $\begin{array}{c}\text { Guidance and } \\
\text { Counselling } \\
\text { Sessions (GS) }\end{array}$ \\
\hline 1. & Use in-group identity markers. & 0 & 1 & 9 \\
2. & Seek agreement. & 0 & 0 & 1 \\
3. & Avoid disagreement. & 2 & 0 & 0 \\
4. $\quad$ Jokes. & 0 & 1 & 0 \\
5. $\quad$ Offer, promise. & 2 & 0 & 1 \\
6. $\quad$ Include both Speaker(S) and Hearer (H) & 0 & 0 & 1 \\
$\quad$ in the activity. & Give gifts to H. & 2 & 2 & 2 \\
\hline & Total No. of Times per Setting & 6 & 4 & 14 \\
\hline
\end{tabular}

the definition of that group. It includes in-group usages of address forms, of language or dialect, of jargon or slang, and of ellipsis. The following excerpts during student-teacher interactions in guidance and counselling (GS) and house assembly (HA) sessions portray this.

1) (GS)

$\mathrm{T}$ : How are you my daughters?

$S(s)$ : We are fine mum.

T: Am happy to hear that. Any other contribution?

S (1): Form ones don't let these boys and even men outside confuse you, AIDs is real my sisters. \{students clap\}

$\mathrm{T}$ : That is true my girls. Let us be responsible over our lives. Life is too short. I would be sad to come bury any of you because of irresponsible choices. Let us respect ourselves and our bodies.

$S$ (2): On behalf of form 1 girls, allow me to thank you, God bless you mum.

$S$ (3): Mum dear please keep guiding us, do not give up on us please, yes we are adolescents but we promise to behave. Asante (thank you) teacher.

In the extract above we can see that address forms have been used to convey in-group membership. According to Brown and Levinson (1987), this strategy involves use of generic names and terms of address like mate, honey, dear, babe, mom, brother, sister, cutie, sweetheart, guys which convey in-group membership. The students use the address forms mum dear, mum, sisters and also pronouns my, we, us, to claim a common ground with the teachers and other students. The use of the address forms and pronouns conveying in-group membership helps to soften the FTA of directly accusing each other of immoral behavior. Use of address forms and pronouns ensures no student feels targeted and hence lessens the threat. The flow of conversation is thus smooth albeit because of the setting and the address forms my daughters which are introduced by the teacher. Use of address forms is positive strategy in that the students feel appre- 
ciated and relative power between them and teachers is minimal.

2) (HA):

S (1): Teacher, someone stole my bag...

$\mathrm{T}$ : When? Ee girls mnaibiana tena! (Girls! Theft is still going on here!)

$S$ (1): Imagine! I went to shower, left it on my bed and didn't get it vile nilicome. (when I came back.)

S (2): Ama kalinusa ndao! (Probably the bag had mandazi (bun) inside) \{Smiling\}

Use of in-group language or dialect is also a form of S explicitly claiming common ground with $\mathrm{H}$. It is a code-switching phenomenon which involves switch from English into a spurious dialect, or a dialect not normally used by $S$ or $\mathrm{H}$, to soften an FTA or turn into a joke. From example 2 above, code switching from English to "sheng" (a mix of Kiswahili and English) is noted during the interactions.

The students are employing code switching from English to "sheng" to soften the element of stealing. To shield the seriousness, one student in HA 2 turns the issue of stealing into a joke by asking if the fellow student forgot a bun in the bag hence it got stolen. This strategy is positive since it seeks to attend to the positive face of the hearer by joking about the sensitive topic of theft and also use of "sheng".

\subsubsection{Use of Seek Agreement Strategy}

This strategy was used only once, in the guidance and counselling session. According to Brown and Levinson (1987), this strategy is employed in two ways: through safe topics and repetition. In the excerpt below, a student in guidance and counselling session used repetition in order to show or seek agreement with the statement made by teacher. This agreement is stressed by repeating part or all of what the preceding speaker has said in the conversation and by using that function to indicate emphatic agreement ("yes", "really", etc.) whenever someone is talking.

3) (GS):

T: Ok, we do not want blame games; this session is meant to guide us to the right direction, are we together?

S: $\quad$ Yes madam, let them stop blame games wengine (some) just love accusations.

From the above excerpt, it can be noted that the student wants to seek agreement with the teacher and thus employs repetition of part of what the preceding speaker which is the teacher in this case says. The use of repetition in GS 3 has been employed by the student to show that both their wants are similar thus the teacher's positive face is saved. This strategy is positive since in the above instance the student shows that the speaker's actions are desirable.

\subsubsection{Use of Avoid Disagreement Strategy}

This strategy was used a total of 2 times in only one setting i.e. staffroom inte- 
raction as explicated in the excerpts below. In the two examples in S1 1 and SI 5 below exhibit the use of token agreement.

4) (SI)

T: $\quad$ Come in! Beatrice, umerudr? (You are back?)

S: $\quad$ Yes Madam, but ... it's ... it's ... Mr. X who has sent me...

T: $\quad$ Ee....

5) (SI)

T: $\quad$ So you transferred because of indiscipline huh?

S: $\quad$ SSeated on the floor crying\} Yes I transferred to this school but because of family issues not indiscipline madam.

Here, there is some level of formality during interactions and the student tries by all means to avoid disagreement with the teacher by using token agreement. This interactional strategy involves use of token agreement, pseudo-agreement, white lies or hedging opinion. Token agreement states that $\mathrm{S}$ may go in twisting their utterances so as to appear to agree or to hide disagreement to respond to a preceding utterance with "Yes, but..." in effect, rather than a blatant "No".

Pseudo-agreement is found in English in the use of then as a conclusory marker, an indication that the speaker is drawing a conclusion to a line of reasoning carried out cooperatively with the addressee. This may refer to a genuine prior agreement;

For example: I'll meet you in front of the theatre just before $8.00 \mathrm{pm}$, then.

Where then points to a conclusion of an actual agreement between $\mathrm{S}$ and $\mathrm{H}$.

White lies are applied where $S$, when confronted with the necessity to state an opinion, wants to lie (“yes I do like your new hat!") rather than damage H's positive face. Hedging opinions states that, alternatively, $\mathrm{S}$ may choose to be vague about his own opinions, so as not to be seen to disagree.

For example: It's really beautiful, in a way.

In two instances, students employ use of token agreement. The two excerpts exemplify this strategy in that the students avoid disagreement by use of token agreement which means that the desire to agree or appear to agree with $\mathrm{H}$ leads also to mechanism for pretending to agree. By use of token agreement, the students save the teachers positive face. Yes, they disagree with the teacher but through appearing to agree first, the teachers thus feel their wants are approved of. This makes it positive strategy.

\subsubsection{Use of Jokes}

Use of jokes is also a strategy evident during the interaction. It is only used once by a student in the house assembly session as exemplified in number 2 above. It is evident that jokes, as a politeness strategy, is not commonly used during interactions between students and teachers in Ndigwa Secondary School. This can be attributed to the subject or nature of interaction. It is only evident in house assembly session. Jokes can be used to stress the fact that there must be some mutual background knowledge and values that $\mathrm{S}$ and $\mathrm{H}$ share. That is why; the strategy of joking may be useful in diminishing the social distance between $\mathrm{S}$ and 
H. In the house assembly session, interaction exemplified by excerpt 2 above, it is noted that a student jokes about the other having left a bun in the bag hence attracting the thief who stole her bag.

From the excerpt it is clear that the students and teachers have mutual relationship. It is the house assembly session and here students regard their teachers as their mothers and fathers thus are free in terms of communication. The use of jokes creates interest in the talk and also diminishes the FTA of one student directly accusing the other of carelessness. This strategy is positive in that the students and teachers claim common ground.

\subsection{Students' Negative Politeness Strategies in Student-Teacher Interactions in Ndigwa Secondary School}

We now turn to look at examples of negative politeness strategies applied in the interactions. Negative politeness is redressive action addressed to the hearer's negative face i.e. their want to have freedom of action unhindered and their attention unimpeded. Brown \& Levinson (1978) identify 10 such strategies but only 4 emerged in our data mainly from classroom interactions. This clearly shows that the use of the negative politeness strategies is employed in a bid to show respect in the staffroom which is the most formal of the three settings. The strategies are summarised in Table 2 and the first three exemplified thereafter.

\subsubsection{Use of Minimize the Imposition (Rx) Strategy}

This strategy is evident 3 times in only one setting, staffroom interaction which is the most formal setting. It is used to minimize one's own action or goods to the addressee. For example, "Could I borrow your pen just for a minute?" In several instances, it is noted that students employ the use of "May I" especially when they need permission to interrupt the teacher. It avoids coercion of the

Table 2. Students' negative politeness strategies evident in student-teacher interactions outside the classroom setting.

\begin{tabular}{|c|c|c|c|c|}
\hline \multirow[b]{2}{*}{ No. } & \multirow[b]{2}{*}{ Negative Politeness Strategies } & \multicolumn{3}{|c|}{ Frequency (No. of Times Evident) } \\
\hline & & $\begin{array}{l}\text { Staffroom } \\
\text { Interaction } \\
\quad(\mathrm{SI})\end{array}$ & $\begin{array}{l}\text { House Assembly } \\
\text { Sessions } \\
\text { (HA) }\end{array}$ & $\begin{array}{l}\text { Guidance and } \\
\text { Counselling } \\
\text { Sessions (GS) }\end{array}$ \\
\hline \multirow[t]{2}{*}{1.} & Minimize the imposition, $\mathrm{Rx}$. & 3 & 0 & 0 \\
\hline & Give deference. & & & \\
\hline \multirow[t]{3}{*}{2.} & a) Give deference to $H$. & 1 & 0 & 0 \\
\hline & b) Use of honorific. & 3 & 0 & 0 \\
\hline & Apologize. & & & \\
\hline \multirow[t]{2}{*}{3.} & a) Beg for forgiveness. & 3 & 1 & 1 \\
\hline & b) Give overwhelming reasons. & 1 & 2 & 1 \\
\hline \multirow[t]{2}{*}{4.} & Impersonalize $\mathrm{S}$ and $\mathrm{H}$. & 0 & 0 & 1 \\
\hline & Total Times per Setting & 11 & 3 & 3 \\
\hline
\end{tabular}


hearer, meaning the speaker seeks clarification by minimizing the threat. The example below attests to this.

6) (SI)

[Student knocks]

S: $\quad$ teacher may I come in?

$\mathrm{T}$ : $\quad$ Yes come in.

7) (SI)

[Student walks in]

S: $\quad$ Nimeambiwa umeniita (Have been told you called for me.)

T: Mbona hujabisha mlango? Rudi nje ubishe kwanza. (Why haven't you knocked? Go out and knock.) (He goes out and knocks the door.)

S: $\quad$ May I come in please.

T: Come in! Where were your manners?! Na wewe ni nani? (Who are you?)

S: $\quad$ Sorry Madam, I am Z.

The above excerpts are all from one setting that is staffroom interaction. The students avoid coercing their teachers. The negative face is threatened in SI 6 when the student just walks in without use of the polite form "May I". This strategy minimizes the imposition on the teacher thus is a negative strategy.

\subsubsection{Use of Give Deference to H-Use of Honorific Strategy}

Use of give deference to $\mathrm{H}$ Strategy is a clear example of courteous regard for people's feelings. Like the minimize imposition strategy above, it is evident in the classroom setting only where it featured 4 times. Use of Give Deference is keen on showing respect to the hearer and in this case it is the teacher. It has been employed in two ways: give deference to $\mathrm{H}$ and use honorific. The students use it during interaction to clearly show the difference in social status between students and teachers. This strategy has two realization of deference: one $S$ humbles and abases himself, and another $\mathrm{S}$ raises $\mathrm{H}$, thus both cases $\mathrm{H}$ is of higher social status than $\mathrm{S}$. It indicates that $\mathrm{H}$ is respected and esteemed and felt to be superior. For example, "Excuse me, Sir, could you show me the way to the bank. The excerpt below illustrates the same.
8) (SI)
S: $\quad$ Excuse me Sir?
T: $\quad$ Yes you are excused.
S: $\quad$ Please where is Mr. X's desk?

The student clearly indicates that the teacher is respected and even superior, thus the student uses the words "excuse me Sir".

Use of honorific terms is also a way to give deference. It aims at avoidance of the use of the first name, insisting on honorific terms like "Dr.", "Mr." etc. during interactions. Students recognize the social distance between them and the teachers and they employ honorific terms like teacher, madam, sir even when the setting and subject is free, for example, in guidance and counseling session or house assembly session. The excerpts below illustrate. 
9) (SI)

T: Oh! Now you want to explain!

S: I ... Mwalimu pole (sorry teacher) I was away...

$\mathrm{T}$ : Where is the evidence? [Approaching the boy]

S: $\quad\{$ Stuttering $\}$ Please teacher let me explain...

10) (SI)

S: $\quad$ Please teacher may I come in?

T: $\quad$ Yes come in.

S: $\quad$ Excuse me Sir?

The use of the honorific terms "teacher" and "sir" brings out the social distance between students and teacher. It shows that the student recognizes the teacher as superior and thus avoids any form of disrespect.

\subsubsection{Use of Apology and Beg for Forgiveness Strategy}

Use of Apology is another strategy used to mitigate the effects of FTA. The strategy was used a total of 9 times in all the three settings in each setting showing the two variations: beg forgiveness and give overwhelming reasons. There are at least four ways to communicate regret or reluctant to do the FTA. Giving overwhelming reason is one such way. It states that $S$ can claim that he has compelling reasons for doing the FTA, thereby it implies that normally the speaker would not dream of impinging H's negative face. Students employed this strategy during interaction especially to get out of situations as in the following examples:

11) (GS)

T: Baba Beryl kindly leave with your daughter.

S: $\quad$ Pleading\} please Sir, please dad I know I have lied to you, please I will speak the truth, I promise please...

12) (HA)

T: $\quad$ Saa ngapi nabado mnaosha! (Why are you still cleaning at this hour?)

S: $\quad$ Mwalimu (Teacher) we woke up very late because the dawn bell didn't ring it was raining.

$S$ (2): Teacher other students refused to leave the house to allow us clean.

$S$ (3): Please teacher I understand we have done wrong please let me explain, I had started working when other students came in from the bathroom and the floor became dirty again.

In these excerpts the students apologize by giving reasons. On normal occasions students would not do that since it would not be apology but justification. The students seek to be understood. This strategy helps to explain the FTA committed, thus is a negative politeness strategy.

Beg forgiveness is also another way to apologize. There are various variants of asking for forgiveness. One can choose self-criticism or apologetic language. For example:

"Sorry to bother you, but...", "I wonder if you could...", "please forgive me..." 
During interaction with teachers in the three settings it can be noted that students beg for forgiveness to get out of situations and also to show remorse. For example, the excerpts below illustrate the same.

13) (SI)

$\mathrm{T}$ : Why did you miss my class?

S: I ... Mwalimu pole (sorry teacher) I was away...

14) (SI)

T: $\quad$ Get up and leave this staffroom now!

S: $\quad$ Please forgive me madam, I am sorry. Let me explain.

I promise to be a good girl please.

15) (GS)

T: [Stands as if to hit the girl] Get out I don't entertain rudeness.

(Parent): Los nyako! (You better talk young girl.)

S: $\quad$ Teacher I am sorry I went to my aunt's place... Please I am sorry.

16) (HA)

T: Enough of your excuses! I don't want to hear any more. I want this place clean and you come for your punishment afterwards.

S: $\quad$ Teacher please understand it is not our fault, please forgive us madam.

From the above excerpts, it is seen that students beg forgiveness during interactions. This strategy aims at making the teacher to cancel the debt implicit in the FTA, the customary use of polite replies e.g. please forgive us, I am sorry, minimizes the imposition hence it is a negative strategy.

\section{Deductions and Recommendations}

Politeness is learned human interactional behaviour that is manifested both linguistically and non-linguistically across cultures. Although much of it is acquired naturally, a good deal happens through instruction. The study looked at three domains in a secondary school setting: Guidance and Counselling sessions (GS), House Assembly sessions (HA) and Staffroom Interaction sessions (CI) as the findings above record. This section presents some deductions and recommendations.

\subsection{Politeness and Instruction}

As stated earlier, politeness strategies are enshrined in the Kenyan school syllabus and are taught at all level (with varying complexity) from pre-school to high school. Secondary school learners therefore are expected to have mastered the use of politeness strategies to a high degree. The study sampled form 1 and form 3 learners to see if there was any notable difference in the use of politeness strategies given that form threes would have had greater exposure. The findings did not reveal any significant difference hence, the analyses in this paper did not consider disaggregation.

Nevertheless, some issues of concern regarding instruction were apparent. For 
example, we see instances where students are limited in the employment of certain strategies. One such case is when they resort to code-switching (English to Swahili/Dholuo) to negotiate in-group identity. The instruction at this level is done in English and the politeness strategies are taught in English. Granted, code-switching is a common and/or natural linguistic phenomena, one wonders whether in the context of politeness interaction the students are not exhibiting their deficiency in the command of English which they have been using from primary school. Alternatively, could it be a recognition that some things are better expressed in the native tongue and should teachers then take cognizance of this when teaching politeness strategies? In example 2 above, a student remarks, "Ama kalinusa ndao" (or there was pan cake aroma) referring to the complaint by another student that his bag had been stolen. The comment serves as a joke lightening a serious issue and comes out effectively in Swahili/Sheng.

Examples 4 and 5 highlighting token agreement strategy are also a good demonstration of how/why students should be taught to master the use of politeness strategies. In these examples, tact is required to express disagreement in a polite and non-offensive way. We insinuated earlier that teachers often complain that some students are rude. The rudeness more often arises from improper usage of politeness strategies. In 5 for example, a student caught in indiscipline wants to agree by denying. He has good reason but fails to put it across. This strategy can also be used tactfully when one is telling a white lie to save face if one has the capability.

The term Please was overly used and in some instances wrongly used. Please is used in different ways like apologizing and showing deference. The students pair it with different politeness strategies that it is now not possible to only tie to deference only. Please according to Cambridge Dictionary is usually associated with politeness. It is used to make a request more polite, for example, can I borrow your pen please? Please is used with imperative form of a verb to express a polite request or order, for example, Please turn to page 10. Whereas in speaking, please is often used to make an order less direct, for example, pass the salt, please. It is also often used to accept something politely, particularly food and drink. It is also used to encourage or more strongly, to beg someone to do something. It can also be used on its own to express disbelief, surprise or annoyance. For example, please, just stop doing that. It's irritating. Oh, please. I can't believe that. However, unlike in the data where please is used in different positions to express request or lessen the directness of an order, standard English posits according to the Cambridge Dictionary that please is used when one asks a question which solicits a favour, not a piece of information. For example, could you pass me that watch, please? How are you, please? The latter merely makes the sentence more polite thus please goes with a request, not a question. The explanation therefore makes the use of please in this study unique. These examples show that the high school students still have a long way to master the use of politeness strategies in English and the teachers need to be aware of this. 


\subsection{Politeness and Power Relations}

The study brought out the issue of power relations that is expected between students and teachers as advanced in the politeness theory. It is shown that power distance increases with the level of formality i.e. the more formal a context is the more magnified the power distance and vice versa. Of the three contexts considered in the study, the staffroom interaction was the most formal while the guidance counselling and house assembly sessions were quite informal. In the informal settings we see the teacher and students operating nearly on the same level. Jokes and endearmentterms are applied. We see this for example in the in-group identity (No. 1) where students refer to their teacher as mum, dear mum and the teacher refers to the students as my daughters. Jokes are used in the house assembly meeting (No. 2). For the staffroom context, we see more of formality e.g. honorific terms. These are seen in nos. 8 and 9 e.g. Excuse me Sir, Mr, Teacher, Mwalimu. The students seemed to draw the distinction in the use of politeness between formal contexts and informal contexts.

\subsection{Politeness in a Cultural Context}

There are expressions of standard social norms that vary from culture to culture as far as politeness is concerned. A good example is in the rules of etiquette. In some African cultures for example, younger people are expected to show respect to their elders by keeping quiet in their presence and only talking when talked to. Similarly, when offered something e.g. a meal, it is considered rude to decline.

From the interactions in the school setting recorded here, we note instances of cultural influence in the students' use of politeness strategies. For example, teacher as a honorific reference is heavily used contrary to standard usage (as can be seen in 9 and 10). A teacher is someone who imparts knowledge. The students however use it as a title in order to avoid the use of the teacher's name. In this cultural context, a teacher (just as a parent) is revered such that mentioning their name is taboo. Other substitute terms commonly used are Sir or Madam. The exchange below from sample 7 is an illustration of a breach of etiquette by the student who doesn't seem to have mastered the relevant politeness strategy.

[Student walks in]

S: $\quad$ Nimeambiwa umeniita (I have been told you called for me.)

T: Mbona hujabisha mlango? Rudi nje ubishe kwanza. (Why haven't you knocked? Go back and knock.) (He goes out and knocks on the door.)

S: $\quad$ May I come in please.

T: Come in! Where were your manners?! Na wewe ni nani? (Who are you?)

S: $\quad$ Sorry Madam, I am Z.

This is a common problem with learners even at this level. The teacher expects the student to knock for clearance to enter the staffroom, address the teacher 
appropriately then begin by introducing himself before stating the need. The student has to be prompted to remember this etiquette. It is very unlikely that this is the order of the etiquette in the student's culture and so he has to learn and consciously apply it.

\section{Conclusion}

From the deductions above we can conclude, that politeness forms are an integral and significant part of language use. Politeness strategies have to be acquired/learned so as to be used appropriately in a given context. Politeness forms can be culturally sensitive. Therefore, instruction in politeness forms through a second/foreign language should take cognizance of this fact.

\section{Conflicts of Interest}

The authors declare no conflicts of interest regarding the publication of this paper.

\section{References}

Brown, P., \& Levinson, S. (1978). Universal in Language Usage: Politeness Phenomena. In E. Goody (Ed.), Questions and Politeness: Strategies in Social Interaction. Berlin: Springer.

Brown, P., \& Levinson, S. (1987). Politeness: Some Universals in Language Usage. Cambridge, UK: Cambridge University Press. https://doi.org/10.1017/CBO9780511813085

Cai, L., Xie, F., \& Peng, L. (2014). A Case Study of College Teacher's Politeness Strategy in EFL Classroom. Theory and Practice in Language Studies, 4, 110-115. https://doi.org/10.4304/tpls.4.1.110-115

Crystal, D. (2008). A Dictionary of Linguistics and Phonetics (6th ed.). Oxford, UK: Blackwell Publishing. https://doi.org/10.1002/9781444302776

Eelen, G. (2001). A Critique of Politeness Theories. Manchester: St. Jerome Publishing.

Gleason, J. B., \& Weintraub, S. (1978). Input Language and Acquisition of Communicative Competence. In N. Keith (Ed.), Children's Language (Vol. 1, pp. 177-222). New York: Gardner Press.

Green, G. M. (1996). Pragmatic and Natural Language Understanding. Hillsdale, NJ: Laurence Erlbaum.

Hassen, R. (2016). Culture-Specific Semiotic Politeness Norms in the Multicultural Society of Ethiopia. Arts and Social Sciences Journal, J7, 168.

Ide, S. (1989). Formal Forms and Discernment: Two Neglected Aspects of Universals on Linguistic Politeness. Multilingua, 8, 223-248. https://doi.org/10.1515/mult.1989.8.2-3.223

Jiang, X. (2010). A Case Study of Teacher's Politeness in EFL Class. Journal of Language Teaching and Research, 1, 651-655. https://doi.org/10.4304/jltr.1.5.651-655

Kenya Institute of Curriculum Development (2002). Secondary Education Syllabus (Vol. 1). Nairobi: Kenya. Kenya Institute of Education.

M'mbohi, W. M. (2016). Emerging Language Use Patterns among Male Football Viewers in Baringo County, Kenya. Unpublished Master's Dissertation, Nairobi, Kenya: Kenyatta University. 
Maisiba, J. O. (2015). Forms of Politeness in Ekegusii: A Sociolinguistic Perspective. Unpublished Master's Dissertation, Nairobi, Kenya: Kenyatta University.

Mburu, C. W. (2011). Sociolinguistic Difference in the Use of Polite Forms by Standard Seven Pupils in Machakos Municipality. Unpublished Master's Dissertation, Nairobi, Kenya: Kenyatta University.

Mwarania, P. K. (2010). Communicative Competence: Use of Polite Forms in a Case Study of Kaaga Girls' High School. Unpublished Master's Dissertation, Nairobi Kenya: Kenyatta University.

Ojwang, B. (2009). Patients Claiming Their Rights: An Analysis of Utterances from a Kenyan Hospital. Southern African Linguistics and Applied Language Studies, 27, 453-469. https://doi.org/10.2989/SALALS.2009.27.4.6.1026

Sacks, H., Schegloff, E. A., \& Jefferson, G. (1974). A Simplest Systematics for the Organization of Turn-Taking for Conversation. Language, 50, 696-735. https://doi.org/10.1353/lan.1974.0010

Sakr, M., Rohlfing, K., Obaid, M., Baxter, P., Weiss, A., Geva, S., \& Salem, M. (2013). Effects of Politeness and Interaction Context on Perception and Experience of HRI (Vol. 8239, pp. 531-541). ICSR 2013. https://doi.org/10.1007/978-3-319-02675-6 53

Watts, J. (2003). Politeness. Cambridge: Cambridge University Press. https://doi.org/10.1017/CBO9780511615184

Yule, G. (1996). Pragmatics. Oxford, UK: Oxford University Press. 